\title{
Assessing Pharmacists' Knowledge of Halal Medications to Support the Health Beliefs of Patients
}

Lakesha Butler, PharmD; Thy Mai, PharmD Candidate; Catherine Santanello, PhD

Southern Illinois University Edwardsville School of Pharmacy

\section{Abstract}

Objectives: The purpose of this study was to explore the knowledge of pharmacists' on Halal medications. In addition, it was a review of Halal medications in order to understand which resources need to be implemented to make this information readily available to support the health beliefs of patients and improve medication adherence.

Methods: Self-administered, anonymous questionnaires were distributed to pharmacists via Qualtrics by email, text message, and social media. Questionnaires assessed pharmacists' knowledge on Halal medications and resources. Inclusion criteria included registered pharmacists working in any healthcare setting.

Results: A total of 121 voluntary pharmacists participated in the study. Over half (57.85\%) of participants reported working in a retail setting. Only $14.05 \%$ had ever served a patient requesting Halal medications. When asked about awareness of Halal medications, only $4.13 \%$ were very aware. While $56.2 \%$ were familiar with dietary restrictions, only $1.65 \%$ were very aware of which medications to substitute if a patient cannot take a prescribed medication due to its ingredients and only $1.65 \%$ were aware of where to look to find alternative Halal medications. Over half of the participants were unaware of Halal pharmaceuticals, Haram ingredients, resources to utilize, or medications to use as an alternative.

Conclusion: Pharmacists are familiar with dietary restrictions due to medications derived from animal products but the majority are unaware of where to search for Halal medication alternatives, ingredients, or products. Resources are needed to make this information readily available. The more informed pharmacists are, the more likely they are to ask the right questions to ensure that patients' religious beliefs are taken into consideration.

Keywords: hala medications, mushbooh, haram, religious beliefs

\section{Introduction}

Many religious beliefs affect medicine use and patient adherence. It is important for pharmacists to be familiar with this topic to serve culturally and spiritually diverse communities in the most optimal manner. Pharmacists should be able to counsel on alternative medications according to patients' beliefs, including Halal medications and ingredients [1]. Although there are many religious restrictions, the focus of this study is on the Islam religion where restrictions include abstaining from animal-derived products not prepared as Halal [2]. In Muslim culture, it is important to know which ingredients are prohibited or permissible. Pigs or any other animal not slaughtered based on Islamic rules are considered Haram and are prohibited for consumption. On the other hand, there are products that are approved for consumption that are classified as Halal. This is important because medications should be Halal certified or be free of animal products in order to be consumed by Muslims. In general, any medication ingredient containing gelatin, glycerol, alcohol stearates, and heparin are not Halal. These ingredients are produced from some form of animal product. Magnesium stearate is used in many tablets but the source could be from either a plant or an animal. If magnesium stearate is listed as an inactive ingredient, this is considered Mushbooh.

Corresponding author: Lakesha M. Butler, PharmD, BCPS

Clinical Professor, Pharmacy Practice

Coordinator, Diversity and Inclusion

Southern Illinois University Edwardsville

Email: Iwiley@siue.edu
Mushbooh means that expert opinions differ in whether this ingredient is considered Halal or Haram. Many widely used medications contain animal or human ingredients; however, information on such ingredients is not always readily accessible to healthcare professionals. Using animal-derived ingredients in this population increases the risk of nonadherence [3-6].

Daher et al. examined pharmacists' views on the effect of spiritual beliefs and medication use and also pharmacists' perspectives on the use of Halal products. However, to the authors' knowledge, there are no studies examining pharmacists' familiarity of Halal medications and the resources available to understand medication ingredients. According to Daher et al., a good pharmacist must be aware of and be prepared to address these issues with patients in a "manner that achieves equilibrium between patients autonomy" and the pharmacist. This means that pharmacists must be knowledgeable about medication ingredients. The majority of health professionals are not aware of animal derived medications that interfere with religious and spiritual beliefs [1]. Sadeeqa et al. explored hospital physicians' perceptions and barriers to prescribing Halal medications; however, there are no studies specifically exploring pharmacists' knowledge and barriers [1, 3-4]. Hence, the goal is to provide a list of common medications for healthcare providers to use as a resource when caring for patients with these restrictions.

When healthcare professionals encounter a patient needing information about a medication ingredient, many may check 
product labeling or contact the manufacturer when unsure. However, manufacturers may not always be able to identify the source of excipients and this process may be difficult due to time constraints [7].

\section{Objectives}

The main objective of this study was to explore pharmacists' knowledge of Halal medications. Additionally, available literature and resources on Halal medications were reviewed to determine gaps in information to support the health beliefs of patients and improve medication adherence.

\section{Methods}

\section{Study settings and design}

An anonymous, electronic, self-administered questionnaire was designed using Qualtrics consisting of 10 questions addressing pharmacists' knowledge of Halal medications. Institutional Review Board exempt status was approved for the study. The survey was available for 3 weeks during summer 2017. No patient identifiable information was recorded. The study was conducted all across the U.S. available to any pharmacists currently practicing in all healthcare fields and interested in participating. Participants were made aware of the study via social media, email, and text messaging. The survey included questions about work setting, frequency of exposure to patients' needing alternative medications, knowledge of Halal medications, and knowledge of resources available to access information about medication ingredients. After the survey period was closed and data was collected and screened, analysis was completed using Qualtrics. Percentages of responses were used to analyze and compare results.

\section{Results}

Of the 121 pharmacists who participated in the survey, $57.85 \%$ $(n=70)$ work in a retail setting, $28.93 \%(n=35)$ hospital setting, $2.48 \%(n=3)$ long term care setting, 3.31\% $(n=4)$ clinic setting, and $7.44 \%(n=9)$ work in another setting including managed care, mail order, pharmaceutical industry, pharmacy benefit manager, hospice, VA, specialty, or academia. When asked about frequency of encounter with patients who need an alternative medication due to health beliefs, only $5.79 \%(n=7)$ have a daily encounter, 9.09\% ( $n=11)$ weekly, 22.31\% ( $n=27)$ monthly, $27.27 \%(n=33)$ yearly, and $35.54 \%(n=43)$ responded never or not applicable.

When asked about resources utilized to search for medication ingredients, $62.5 \%$ ( $n=75)$ utilize an online resource, $21.67 \%$ $(n=26)$ look at package inserts, $11.67 \%(n=14)$ call the manufacturer, $4.17 \%(n=5)$ utilize multiple resources and no participant utilizes a physician or another pharmacist for questions about medication ingredients. This reinforces the importance of having a readily accessible online resource with Halal medications and medication ingredients for all healthcare professionals to utilize. One participant opted out of answering the question regarding resources used, and commented that the resources used are dependent on the question asked. The data was still collected and percentages were used to analyze the data out of 120 participants instead of 121 participants for that question only.

Although $57.85 \%$ of participants work in a retail setting, roughly only $14 \%$ had ever served a patient requesting Halal medications [Table 1]. From the survey questions pertaining to awareness of Halal medications, only $4.13 \%$ were very aware while $27.27 \%$ were somewhat aware, and the vast majority (nearly 69\%) were unaware. When asked if they were aware that certain health beliefs prevent consumption of animal products, $56.2 \%$ were very aware while $41.32 \%$ were somewhat aware. Referring to the data, many pharmacists know about certain health beliefs that prohibit the consumption of animal products but many are not aware of the term Halal which demonstrates the importance of this topic and the needed provision of resources for Halal medications. While $56.2 \%$ were aware of dietary restrictions, only $1.65 \%$ were very aware of which medications to substitute if a patient cannot take a prescribed medication due to its ingredients.

\section{Discussion}

This data suggests that pharmacists are aware of specific dietary restrictions for certain patient populations but the majority are not aware of 1 ) where to search for alternative medications and medication ingredients, 2) if a medication is Halal or Haram, or 3) which ingredients are considered Halal or Haram. This supports the belief that it is necessary for a resource to be available for quick access and information to ensure that patients receive optimal care and are adherent to their treatment. There are no quick, concise resources for pharmacists to access information about Halal medications or to determine if the ingredients in medications are derived from animal or plant sources. If asked what ingredients are in a medication, the pharmacist would have to look in the package insert or may have to call the manufacturer, which is often difficult due to time constraints. Frequently, the manufacturer does not readily know if an ingredient is derived from animal or plant sources and may have to contact their supplier to determine that information. The information in this study can be a resource for to aid pharmacists in determining which medication alternatives are appropriate for patients due to religious beliefs or dietary restrictions in a concise and quickly accessible manner. Approximately $70 \%$ of participants reported encountering a patient needing an alternative medication due to health beliefs [Figure 2]. This shows that this underserved population does exist. Implementation of resources to make this information more available for quick access as well as to provide awareness on this particular underserved population is needed. 
It is best to call the manufacturer to determine if products such as magnesium stearate are derived from an animal or plant source. This is similar for products containing gelatin or glycerol commonly in capsule dosage forms. Gelatin and glycerol components may be derived from an animal or plant source which can be determined by calling the manufacturer. The ingredients listed in Table 2 are common ingredients that are non-Halal and should be taken into consideration when dispensing a medication to a patient with restrictions. The list also includes ingredients considered Mushbooh such as polyethylene glycol which is a questionable ingredient that in some cases is considered Haram and in others Halal. The ingredients magnesium stearate and glycerin are considered Halal if it originated from a plant source and Haram if originated from an animal source. The list is not all-inclusive but provides the commonly used ingredients in some popular medications. There are many other ingredients considered Mushbooh and Haram [5].

A list of common medication alternatives with no animal, lactose, or alcohol ingredients is provided for accessible information about appropriate medications that may be permissible to be consumed as well as a list of non-Halal ingredients to look for when unsure. The table of alternative medications was compiled from the best information available, but cannot be regarded as comprehensive and manufacturers may vary in the ingredients used [Table 2]. Product ingredients were collected from package inserts and by contacting manufacturers directly. Information of ingredient sources were given by manufacturers to the best of their knowledge. The medications listed were found to be free from an animal product, lactose, or alcohol ingredients. However, some ingredients do contain polyethylene glycol and in some cases may be considered Haram and in other cases, considered Halal. It is best to discuss this with patients before initiating therapy. Other manufacturers not listed may differ in their inactive ingredient sources. The list provided contains common prescription and over-the-counter medications that have no animal ingredients or derivatives in the product as confirmed by the manufacturers. Some manufacturers did state that their company does not test for trace amounts of substances that may be present in the ingredients as a result of the manufacturing process. The source of magnesium stearate and other ingredients listed were all derived from plant sources as confirmed by the manufacturers, although the ingredient suppliers may change at any point without notice. It is best to reconfirm with manufacturers when looking for alternative therapies and this guide is available to be used as a reference [8-13].

If an alternative is not available from manufacturers, a compounded medication may be available. Pharmacies may be able to compound medications without animal derived ingredients, lactose, or alcohol to support patients' health beliefs. To find over-the-counter supplements, NOW Foods has Halal certified products available to order at www.NOWfoods.com [14]. These products are Halal certified and are not derived from any animal sources. It is also important to note that the general Islamic opinion is that if lifesaving measure are needed and there is no alternative, Haram product consumption is acceptable. However, this choice should be made by the patient. Also, many Muslims may not be aware that some medications contain Haram products. Future studies are needed to investigate Muslim awareness of medications containing Haram or Mushbooh products and the current perceptions of using them.

In addition to the need to educate practicing pharmacists, this information could have a positive impact on pharmacy education. This could be a topic added to the pharmacy curriculum to aid in preparing students to be culturally sensitive and interact with diverse patient populations as outlined in the Accreditation Council of Pharmacy Education (ACPE) standards [15]. It is recommended that faculty who are involved in courses that address cultural competency are educated on Halal medications and resources, and that their students can confidently serve the needs of patients requesting Halal medications when they become practicing pharmacists.

\section{Limitations}

The limitations of this study include the time limit on the survey. If the survey had been available over a longer period of time, it may have reached a broader audience and received greater response. In addition, the survey participants may not reside in an area that is socially and culturally diverse with respect to this and other underserved populations. A more diverse area may have resulted in more pharmacists encountering patients with this particular need. The authors did not assess the pharmacists' demographic area or years of employment, which could help determine the exposure to this population of patients. Other limitations include some manufacturers not knowing where the source of ingredients was derived from and could not provide information due to the requested information being undocumented. Additionally, the ingredients from suppliers may change at any time without notice so this list may need to be updated frequently. Further studies can assess other manufacturers and ingredients in common medications.

\section{Conclusion}

Based on the findings of this study, the authors conclude that pharmacists may be aware of dietary restrictions due to medications derived from animal products, but many are not aware of where to search for Halal medication alternatives, ingredients, or products. Resources are needed to make this information readily available as well as education to provide awareness on this culturally diverse and underserved 
population. The more informed pharmacists are, the more likely they are to ask the right questions to ensure patients' religious beliefs are taken into consideration. If patients know a certain medication is acceptable to their religious beliefs or dietary restrictions, they may be more willing to take that particular medication. This can result in enhanced medication adherence as well as the promotion of trust between the health care professional and patient.

Acknowlegements: None

Funding: None

\section{References}

1. Daher, M., Chaar, B., and Saini, B. Impact of patients' religious and spiritual beliefs in pharmacy: From the perspective of the pharmacist. Research in Social and Administrative Pharmacy. 2015; 11: e31-e41

2. Department of Health: Guidelines for the use of medicines/pharmaceuticals of animal origins 2013. Available at:

https://www.health.qld.gov.au/ data/assets/pdf fi le/0024/147507/qh-gdl-954.pdf. Accessed July 20, 2017.

3. Eriksson, A., Burcharth, J., and Rosenberg J. Animal derived products may conflict with religious patients' beliefs. BMC Medical Ethics. 2013; 14:48

4. Sadeeqa, S., Sarriff, A., Masood, I. et al. Kap among doctors working in hospitals, regarding Halal pharmaceuticals; a cross sectional assessment. Acta Poloniae Pharmaceutica- Drug Research. 2015; 72(3): 615-625

5. Sarriff, A., Akram, H., and Razzaq, A. Exploring the Halal status of cardiovascular, endocrine, and respiratory group of medications. Malays J Med Sci. 2013; 20(1): 69-75
6. AzilahHusin, N., Ghazali, A., Roslan, F, Bahrain, M. Halal Medicine: Do doctors have the true awareness? ljaber. 2015; 13(7): 5175-5186

7. Strickland S. Dietary restrictions: implications on medication choice. British Journal of General Practice. 2014; e670

8. Hoesli, T., Smith, K. Effects of Religious and Personal Beliefs on Medication Regimen Design. Orthopedics. 2011; 34(4): 292-295

9. Ogden, J. Religious constraints on prescribing medication. Prescriber. 2016; 47-51

10. Moktar, H., Aziz, N., Harasstani, O., et al. Permissibility Halal-status of cardiovascular medications in Malaysia. Int. J. Adv. Res. 2016; 4(12): 2119-2126

11. Halal scan. Sharia Board New York. Available at: http://www.shariahboardny.org. Accessed August 3, 2017.

12. DailyMed. U.S. National Library of Medicine. National Institute of Health. Available at: https://www.nlm.nih.gov/. Accessed October 13, 2017.

13. Medicine. Halal in USA. 2016. Available at: http://www.halalinusa.com/medicine/. Accessed October 14, 2017.

14. Supplements. NOW foods. 2017. Available at: https://www.nowfoods.com/supplements. Accessed October 14, 2017.

15. Accreditation Council for Pharmacy Education. Accreditation Standards and Key Elements for the Professional Program in Pharmacy Leading to the Doctor of Pharmacy Degree ("Standards 2016"). Published February 2015. Available at: https://www.acpeaccredit.org/pdf/Standards2016FINAL.pdf. Accessed June 27, 2018. 
Table 1: Pharmacists' knowledge of Halal pharmaceuticals

\begin{tabular}{|l|c|c|c|}
\hline \multicolumn{1}{|c|}{ Statements } & \multicolumn{2}{|c|}{ Reponses } \\
\cline { 2 - 4 } & $\begin{array}{c}\text { Very Aware } \\
n(\%)\end{array}$ & $\begin{array}{c}\text { Somewhat Aware } n \\
\text { (\%) }\end{array}$ & $\begin{array}{c}\text { Not Aware } \\
n \text { (\%) }\end{array}$ \\
\hline Are you aware of Halal medications? & $5(4.13)$ & $33(27.27)$ & 83 (68.60) \\
\hline $\begin{array}{l}\text { Are you aware that some patients with certain health } \\
\text { beliefs cannot consume specific ingredients in medications } \\
\text { that are derived from animal products? }\end{array}$ & $68(56.20)$ & $50(41.32)$ & $3(2.48)$ \\
\hline $\begin{array}{l}\text { Are you aware of which ingredients in medications are } \\
\text { Haram (prohibited in Muslim culture)? }\end{array}$ & $5(4.13)$ & 51 (42.15) & 65 (53.72) \\
\hline $\begin{array}{l}\text { Are you aware of where to look to find if a medication is } \\
\text { Halal or Haram? }\end{array}$ & $4(3.31)$ & $25(20.66)$ & $92(76.03)$ \\
\hline $\begin{array}{l}\text { Are you aware of which medications to substitute if the } \\
\text { patient cannot take a prescribed medication due to its } \\
\text { ingredients? }\end{array}$ & $2(1.65)$ & 41 (33.88) & 78 (64.46) \\
\hline $\begin{array}{l}\text { Are you aware of where to look to find alternative } \\
\text { medications that are Halal? }\end{array}$ & $2(1.65)$ & $22(18.18)$ & 97 (80.17) \\
\hline
\end{tabular}


Table 2: Common medications with no animal, lactose, or alcohol ingredients ${ }^{11-13}$

\begin{tabular}{|c|c|c|}
\hline \multicolumn{3}{|c|}{ List of medications containing no animal, lactose, or alcohol ingredients } \\
\hline Indication & Medication & Manufacturer \\
\hline \multirow[t]{8}{*}{ Hypertension } & Valsartan tablets & AvKARE* \\
\hline & Lisinopril tablets & Lupin, Accord \\
\hline & Metoprolol succinate ER tablets & Par* \\
\hline & Spironolactone tablets & Par* \\
\hline & Methyldopa tablets & Accord \\
\hline & Atenolol tablets & AvKARE \\
\hline & Amlodipine tablets & AvKARE \\
\hline & Irbesartan tablets & AvKARE \\
\hline Gout & Allopurinol tablets & Par \\
\hline Thyroid & Levothyroxine & Mylan \\
\hline \multirow[t]{5}{*}{ Depression } & Sertraline tablets & Aurobindo*, Lupin*, Accord* \\
\hline & Fetzima capsules & Allergen \\
\hline & Escitalopram tablets & Accord*, Aurobindo* \\
\hline & Citalopram solution & West-Ward \\
\hline & Trintellix tablets & Takeda \\
\hline \multirow[t]{2}{*}{ Antipsychotics } & Aripiprazole tablets & Amneal \\
\hline & Olanzapine injection & Lilly \\
\hline Asthma & Montelukast tablets & Accord* \\
\hline Alzheimer's Disease & Memantine tablets & Aurobindo* \\
\hline \multirow[t]{6}{*}{ Diabetes } & Alogliptin tablets & Takeda \\
\hline & Glyburide tablets & Aurobindo, AvKARE \\
\hline & Metformin IR/ER tablets & Amneal, Aurobindo*, Heritage, AvKARE \\
\hline & Trulicity & Lilly \\
\hline & Bydureon & AztraZeneca \\
\hline & Byetta & AztraZeneca \\
\hline Neuropathy & Gabapentin tablets & Aurobindo, AvKARE \\
\hline \multirow[t]{3}{*}{ Osteoporosis } & Ibandronate tablets & Aurobindo \\
\hline & Alendronate tablets & Aurobindo \\
\hline & Zoledronic Acid injection & Accord \\
\hline Antiviral & Valacyclovir tablets & Aurobindo* \\
\hline Antifungal & Metronidazole tablets & Aurobindo \\
\hline \multirow[t]{8}{*}{ Antibiotics } & Levofloxacin tablets & Aurobindo*, Camber \\
\hline & Amoxicillin oral suspension & Aurobindo \\
\hline & Ciprofloxacin tablets & Aurobindo* \\
\hline & Sulf/Trim tablets (Bactrim) & Aurobindo, AvKARE \\
\hline & SMZ/TMP (Bactrim DS) tablets & Amneal \\
\hline & Amoxicillin/ clav tablets & Aurobindo* \\
\hline & Amoxicillin/clav oral suspension & Aurobindo \\
\hline & Cefdinir oral suspension & Lupin, Aurobindo \\
\hline \multirow[t]{3}{*}{ Pain } & Morphine sulfate injection & Simplist \\
\hline & Dilaudid hydromorphone injection & Simplist \\
\hline & Advil tablets & Pfizer \\
\hline \multirow{5}{*}{ GERD/ Acid Reflux } & Nexium $24 \mathrm{~h}$ tablets & Pfizer \\
\hline & Famotidine tablets & Aurobindo \\
\hline & Ranitidine tablets & Amneal, AvKARE \\
\hline & Esomeprazole sodium injection & Accord \\
\hline & Dexilant capsule & Takeda \\
\hline \multirow[t]{2}{*}{ Antiplatelet } & Aspirin & Bayer \\
\hline & Clopidogrel tablet & Accord, Camber* \\
\hline Motion Sickness & Metoclopramide injection & Simplist \\
\hline
\end{tabular}




\section{Student Paper}

\begin{tabular}{|l|l|l|}
\hline \multirow{4}{*}{ Cough } & Ondansetron injection & Simplist, Accord \\
\hline \multirow{4}{*}{ Cold/flu } & Delsym 12HR liquid & Reckitt Benckiser* \\
\cline { 2 - 3 } & Robitussin 12HR oral suspension & Pfizer \\
\hline \multirow{4}{*}{ Antacid } & $\begin{array}{l}\text { Alcohol Free NyQuil Cold and Flu } \\
\text { Relief liquid }\end{array}$ & Proctor \& Gamble* \\
\cline { 2 - 3 } & DayQuil Cold and Flu liquid & Proctor \& Gamble \\
\hline \multirow{5}{*}{ Allergy } & Tums & Glaxo-Smith Kline \\
\cline { 2 - 3 } & Alka-Seltzer ReliefChews & Bayer \\
\cline { 2 - 3 } & Maalox liquid & Novartis \\
\cline { 2 - 3 } & Pepto Bismol liquid & Proctor \& Gamble \\
\hline \multirow{5}{*}{ Diarrhea } & Dexamethasone sodium phosphate & Simplist \\
\cline { 2 - 3 } & injection & Bayer* \\
\cline { 2 - 3 } & Afrin original nasal spray & Sanofi \\
\cline { 2 - 3 } & Nasacort nasal spray & Johnson \& Johnson \\
\hline Constipation & Imodium liquid & Glaxo-Smith Kline \\
\cline { 2 - 3 } & $\begin{array}{l}\text { Imodium Multi-symptom relief } \\
\text { caplets }\end{array}$ & \\
\hline
\end{tabular}

*Contains polyethylene glycol which is a questionable ingredient and opinions differ on whether this product is Halal or Haram. 